\title{
Is DHT production by $5 \alpha$-reductase friend or foe in prostate cancer?
}

\section{Takeo Kosaka* , Akira Miyajima and Mototsugu Oya}

Department of Urology, Keio University School of Medicine, Tokyo, Japan

\section{Edited by:}

Fabio Grizzi, Humanitas Clinical and Research Center, Italy

\section{Reviewed by:}

Elena Ranieri, University of Foggia, Italy

Fabio Grizzi, Humanitas Clinical and Research Center, Italy

\section{*Correspondence:}

Takeo Kosaka, Department of Urology, Keio University School of Medicine, 35 Shinanomachi, Shinjuku-ku, Tokyo 160-8582, Japan e-mail: takemduro@gmail.com

\begin{abstract}
The first advance in the history of studies on prostate cancer (PCa) and androgens was the development of treatment with castration and administration of estrogen by Charles B. Huggins, who won the Nobel Prize in Physiology and Medicine. Since then, and for 70 years, androgen deprivation therapy has been the standard therapy for advanced PCa and the center of studies on PCa. However, recent advances have shed light on the relationship between androgens and the development or the progression of PCa. The use of 5AR inhibitors to prevent progression of PCa continues to be widely discussed. Discussion has been fueled by the findings of two large randomized, placebo-controlled trials: the Prostate Cancer Prevention Trial with finasteride and the Reduction by Dutasteride of Prostate Cancer Events trial. Does the development of PCa or progression to castration-resistant PCa depend on dihydrotestosterone (DHT)? Here, we summarize and discuss recent topics of local androgen production of DHT in PCa.
\end{abstract}

Keywords: prostate cancer, androgen receptor, steroidogenesis, $5 \alpha$-reductase inhibitors, C4-2AT6

\section{INTRODUCTION}

Prostate cancer $(\mathrm{PCa})$ is a malignant tumor that has high morbidity in Europe and the United States, i.e., the first among the male cancers and the second leading cause of death due to cancer in the United States. The morbidity of PCa has also been increasing also in Japan, partly because of the widespread practice of checkup using prostatic-specific antigen (PSA). Thus, huge amounts of research funds are directed to studies given for studies on PCa and this very competitive field has made remarkable advances.

The first progress in the history of studies on PCa and androgens was the development of treatment with castration and administration of estrogen by Charles B. Huggins, who won the Nobel Prize in Physiology and Medicine (1). Since then, and for 70 years, androgen deprivation therapy (ADT) has been the standard therapy for advanced PCa and the center of studies on PCa. However, accumulating evidence has shed light on the relationship between the development and progression of $\mathrm{PCa}$ or castration-resistant prostate cancer (CRPC) and androgen-androgen receptor axis (AR axis) (2-7).

On the other hands, the use of $5 \alpha$-reductase inhibitors (5AR): finasteride or dutasteride among the AR axis targeting drug to prevent development or progression of PCa continues to be widely discussed. Controversies have been fueled by the results of two large randomized, placebo-controlled trials: the Prostate Cancer Prevention Trial (PCPT) with finasteride (8) and the Reduction by Dutasteride of Prostate Cancer Events (REDUCE) trial (9).

Here, we summarize and discuss recent topics of local androgen production and $5 \alpha$-reductase in PCa.

\section{AR AXIS: ANDROGEN RECEPTOR IN PROSTATE CANCER TISSUES}

Prostate-specific antigen is a tumor marker commonly used in clinical practice to screen patients with PCa. Consequently, the percentage of men in whom localized PCa has been detected has been increasing; these men are expected to receive complete treatment, including radical prostatectomy and various radiotherapies. However, unfortunately until now, there are many patients with advanced cancer and poorly differentiated carcinoma of high Gleason score and patients who develop a recurrent tumor or metastasis after radical treatment. Most of these patients are treated with ADT (10). However, this therapy has a transient effect, and patients develop hormone-refractory prostate cancer (HRPC), which is resistant to ADT, within several years. AR plays an important role in the advancement of PCa even in patients who undergo castration $(11,12)$. Since AR is considered to be substantially involved in the pathophysiology of HRPC, this PC is also called CRPC.

The results of studies using cell lines and those on AR expression in patients with PCa showed that AR expression was maintained or enhanced even after ADT in many patients and there is evidence of AR expression in CRPC. Gene expression was analyzed using xenograft models of different PCas and enhanced AR mRNA expression was found to be a common factor of acquired ADTresistance in many cancer cell strains, showing that cells also respond to a low concentration of androgen (13). On the other hand, reduced AR expression may be controlled epigenetic control by DNA methylation in promotor region may be involved in the mechanism of advanced CRPC (14). It was found that mutations occurred in highly expressed AR and the AR structure was changed downstream of the IL- 6 and EGF signaling pathways via STAT3/MAPK-mediated phosphorylation, resulting in AR activation (15-17). It was also found that the expression of co-activators enhancing AR transcriptional activity increased in CRPC, leading to enhanced AR transcriptional activity (7).

\section{AR AXIS: ANDROGEN PRODUCTION IN PROSTATE CANCER TISSUES}

Recent progress has revealed intratumoral conversion of adrenal androgens; namely de novo steroid synthesis has been proposed 
as potential causes of PCa progression $(18,19)$. Results of these studies provide the molecular basis for the inhibition of androgen production and nuclear import of mutated AR in CRPC tissues, leading to actual drug discovery and clinical trials (20-27). The reported high intratumoral testosterone and dihydrotestosterone (DHT) concentrations left in CRPC patients with castrated serum androgen levels have suggested that CRPC maintains a clinically relevant dependence on AR signaling axis. AR activation by androgens converted from adrenal androgens or synthesized intratumorally via the de novo route has been proposed as one of the mechanisms of castration resistance $(19,28-31)$. Some studies using CRPC cancer tissue have investigated intraprostatic testosterone or the active metabolites in quantities, which is thought to be sufficient to stimulate AR-mediated gene expression (32-34). Recent papers have reported that men with a Gleason score of $>7$ had lower intraprostatic DHT than men with a Gleason score of $<6$, suggesting that a low-androgen microenvironment predisposes to development or progression for high-grade PCa or CRPC (35-37).

Dihydrotestosterone is the most active androgen, and it was observed that its concentration in PCa tissues did not decrease to the concentration after castration even during ADT and that DHT was produced from adrenal androgen $(18,19)$. Although $5 \mathrm{AR}$, which is essential for DHT biosynthesis, was identified at the mRNA level in human CRPC metastases (29-31, 38), physiologically relevant $5 \mathrm{AR}$ activity in human CRPC has not yet been fully demonstrated.

Recently, authors have just reported a useful experimental model of human CRPC (39-44). We cultured AR positive, PTENnull, and PSA producing CRPC cell line C4-2 for more than 6 months under androgen ablation media. We were able to establish stable cell line and named it C4-2AT6. These cells seem to harbor aggressive angiogenic properties and elevated phosphorylated Akt expression. These two cell lines may reproduce some part of clinical human CRPC progression and offer an excellent experimental model system with which to investigate complicated biology of CRPC. Using this experimental model, we examined the sequential biosynthesis of DHT from each androgen and were able to find the decreased biosynthesis of DHT in CRPC. To ascertain the 5ARI activity, we co-cultured C4-2 and C4-2AT6 cells with the 13C labeled steroid precursor: 13C-Adione. We examined the sequential biosynthesis of the androgens 13C-T and 13C-DHT, and obtained direct evidence of de novo sequential biosynthesis of androgens in both human CRPC cells. CRPC cells were found to express 5AR activity and the activities were thought to be changed under androgen ablation and 5AR activity was not necessarily paralleled by SRD5As expression. To determine whether finasteride and dutasteride have inhibitory effects of the conversion into DHT in CRPC cells, we investigated the concentration of 13C-DHT after treatment with finasteride and dutasteride. LC/MS/MS analysis could not identify 13C-DHT in human CRPC cells. These results indicate that finasteride and dutasteride were able to abrogate the conversion into 13C-DHT in CRPC cells, although finasteride and dutasteride themselves did not have an inhibitory effect on human CRPC (45).

Recently, evidences have shed light on the relationship between $\mathrm{AR}$ axis and the PCa development or acquisition of castration resistance (2-5). The use of 5ARIs to prevent progression of PCa is controversial because of the results from recent two large randomized, placebo-controlled PCPT (8) and REDUCE trials (9). The PCPT trial was the first large-scale study to examine the effect of finasteride in relation to PCa development. PCa detected in patients treated with finasteride were of a higher grade than those in patients administered a placebo. High Gleason scores between 7 and 10 were found in $6.4 \%$ of the tumors in the finasteride group, compared with only $5.1 \%$ of those in the placebo group. The REDUCE trial revealed an overall reduction in the number of PCa patients with a low Gleason score of 5-6 in those receiving dutasteride versus those given a placebo (19.9\% compared to $25.1 \%$, respectively). However, during 4 -year periods, PCa with high Gleason score of 8-10 were more continual in the dutasteride-treated group than in the placebo group. The FDA analyzed these trials and cited the fact that the obligate increased incidence of tumors with Gleason scores between 8 and 10 by $0.7 \%$ with finasteride and by $0.5 \%$ with dutasteride. The US Food and Drug Administration's Oncologic Drugs Advisory Committee voted against recommending 5ARI for the indication to decrease PCa risk in December 2010, because the risk of induction of aggressive PCa outweighed their potential indication for PCa chemoprevention (4). These observations still cannot be fully explained from the view point based on mechanistic analysis. These results suggest that finasteride or dutasteride has little or no effect on more aggressive tumors with high Gleason scores. The decision by FDA not to approve the use of 5ARIs to prevent $\mathrm{PCa}$ indicates that further basic and clinical investigations are warranted.

Does the process to CRPC from androgen-dependent PCa depend on DHT produced by $5 \alpha$-reductase from testosterone? Is it still clinically achievable to treat CRPC using 5ARIs? The efficacies of 5ARIs on metastatic CRPC have not yet been evaluated.

The decreased 5AR activity that we observed in C4-2AT6 cells with the property of human CRPC raised an important critical question: does the death or alive of C4-2AT6 cells depend on DHT? Thus, we examined the effects of DHT on C4-2 and C42AT6 cells $(40,43,45)$. These human CRPC cells exhibited reduced cell viability when treated with DHT at the dose-dependent manner (45). C4-2 and C4-2AT6 cells exhibit elevated and functional $\mathrm{AR}$ expression and produce PSA in response to DHT in a dosedependent manner; however, C4-2AT6 cells showed significantly lower cell viability. The suppressive effect of DHT on PCa cells is not limited to these in vitro results. Some recent clinical studies showed that CRPC could be treated with androgens because of the inhibitory effect of excess androgens (40, 46-49). Accumulating data has represented that AR has a finite ability to bind to T or DHT. However, at higher concentrations, T or DHT has no further additive effect on PCa cell viability when all ARs are bound to T or DHT $(40,46-50)$. These events are termed as a saturation point. Because of this saturation point, excess DHT may result in the suppression of androgenic-induced proliferation of these cells. We think that CRPC cells have an unknown regulatory system to protect themselves from the excessive androgen with suppressive effects by $5 \mathrm{AR}$ activity, although further investigation is needed. 


\section{CONCLUSION}

We reviewed in this article a large number of studies on PCa, which are selected and reviewed from the viewpoint of the authors. For other topics, other valuable articles are available for references.

To resolve many clinical problems and give benefit to the patients, we should actively join basic studies, which lead to multilateral understanding of many valuable basic and clinical studies.

\section{REFERENCES}

1. Huggins C, Hodges CV. Studies on prostatic cancer - I. The effect of castration, of estrogen and of androgen injection on serum phosphatases in metastatic carcinoma of the prostate. Cancer Res (1941) 1(4):293-7.

2. Morgentaler A, Traish AM. Shifting the paradigm of testosterone and prostate cancer: the saturation model and the limits of androgen-dependent growth. Eur Urol (2009) 55(2):310-20. doi:10.1016/j.eururo.2008.09.024

3. Morgentaler A. Testosterone and prostate cancer: an historical perspective on a modern myth. Eur Urol (2006) 50(5):935-9. doi:10.1016/j.eururo.2006.06.034

4. Theoret MR, Ning YM, Zhang JJ, Justice R, Keegan P, Pazdur R. The risks and benefits of 5alpha-reductase inhibitors for prostate-cancer prevention. $\mathrm{N} \mathrm{Engl} \mathrm{J}$ Med (2011) 365(2):97-9. doi:10.1056/NEJMp1106783

5. Walsh PC. Chemoprevention of prostate cancer. N Engl J Med (2010) 362(13):1237-8. doi:10.1056/NEJMe1001045

6. Logothetis CJ, Gallick GE, Maity SN, Kim J, Aparicio A, Efstathiou E, et al. Molecular classification of prostate cancer progression: foundation for marker-driven treatment of prostate cancer. Cancer Discov (2013) 3(8):849-61. doi:10.1158/ 2159-8290.CD-12-0460

7. Mills IG. Maintaining and reprogramming genomic androgen receptor activity in prostate cancer. Nat Rev Cancer (2014) 14(3):187-98. doi:10.1038/nrc3678

8. Thompson IM, Goodman PJ, Tangen CM, Lucia MS, Miller GJ, Ford LG, et al. The influence of finasteride on the development of prostate cancer. N Engl J Med (2003) 349(3):215-24. doi:10.1056/NEJMoa030660

9. Andriole GL, Bostwick DG, Brawley OW, Gomella LG, Marberger M, Montorsi F, et al. Effect of dutasteride on the risk of prostate cancer. N Engl J Med (2010) 362(13):1192-202. doi:10.1056/NEJMoa0908127

10. Hellerstedt BA, Pienta KJ. The current state of hormonal therapy for prostate cancer. CA Cancer J Clin (2002) 52(3):154-79. doi:10.3322/canjclin.52.3.154

11. Taplin ME. Drug insight: role of the androgen receptor in the development and progression of prostate cancer. Nat Clin Pract Oncol (2007) 4(4):236-44. doi:10.1038/ncponc0765

12. Scher HI, Sawyers CL. Biology of progressive, castration-resistant prostate cancer: directed therapies targeting the androgen-receptor signaling axis. J Clin Oncol (2005) 23(32):8253-61. doi:10.1200/JCO.2005.03.4777

13. Chen CD, Welsbie DS, Tran C, Baek SH, Chen R, Vessella R, et al. Molecular determinants of resistance to antiandrogen therapy. Nat Med (2004) 10(1):33-9. doi: $10.1038 / \mathrm{nm} 972$

14. Nakayama T, Watanabe M, Suzuki H, Toyota M, Sekita N, Hirokawa Y, et al. Epigenetic regulation of androgen receptor gene expression in human prostate cancers. Lab Invest (2000) 80(12):1789-96. doi:10.1038/labinvest.3780190

15. Ueda T, Bruchovsky N, Sadar MD. Activation of the androgen receptor Nterminal domain by interleukin-6 via MAPK and STAT3 signal transduction pathways. J Biol Chem (2002) 277(9):7076-85. doi:10.1074/jbc.M108255200

16. Chen T, Wang LH, Farrar WL. Interleukin 6 activates androgen receptormediated gene expression through a signal transducer and activator of transcription 3-dependent pathway in LNCaP prostate cancer cells. Cancer Res (2000) 60(8):2132-5.

17. Unni E, Sun S, Nan B, McPhaul MJ, Cheskis B, Mancini MA, et al. Changes in androgen receptor nongenotropic signaling correlate with transition of LNCaP cells to androgen independence. Cancer Res (2004) 64(19):7156-68. doi:10.1158/0008-5472.CAN-04-1121

18. Montgomery RB, Mostaghel EA, Vessella R, Hess DL, Kalhorn TF, Higano $\mathrm{CS}$, et al. Maintenance of intratumoral androgens in metastatic prostate cancer: a mechanism for castration-resistant tumor growth. Cancer Res (2008) 68(11):4447-54. doi:10.1158/0008-5472.CAN-08-0249

19. Stanbrough M, Bubley GJ, Ross K, Golub TR, Rubin MA, Penning TM, et al. Increased expression of genes converting adrenal androgens to testosterone in androgen-independent prostate cancer. Cancer Res (2006) 66(5):2815-25. doi:10.1158/0008-5472.CAN-05-4000

20. Molina A, Belldegrun A. Novel therapeutic strategies for castration resistant prostate cancer: inhibition of persistent androgen production and androgen receptor mediated signaling. J Urol (2011) 185(3):787-94. doi:10.1016/j.juro. 2010.10.042

21. Ryan CJ, Smith MR, Fong L, Rosenberg JE, Kantoff P, Raynaud F, et al. Phase I clinical trial of the CYP17 inhibitor abiraterone acetate demonstrating clinical activity in patients with castration-resistant prostate cancer who received prior ketoconazole therapy. J Clin Oncol (2010) 28(9):1481-8. doi:10.1200/JCO.2009. 24.1281

22. Reid AH, Attard G, Danila DC, Oommen NB, Olmos D, Fong PC, et al. Significant and sustained antitumor activity in post-docetaxel, castration-resistant prostate cancer with the CYP17 inhibitor abiraterone acetate. J Clin Oncol (2010) 28(9):1489-95. doi:10.1200/JCO.2009.24.6819

23. Danila DC, Morris MJ, de BonoJS, Ryan CJ, Denmeade SR, Smith MR, et al. Phase II multicenter study of abiraterone acetate plus prednisone therapy in patients with docetaxel-treated castration-resistant prostate cancer. J Clin Oncol (2010) 28(9):1496-501. doi:10.1200/JCO.2009.25.9259

24. Chen Y, Clegg NJ, Scher HI. Anti-androgens and androgen-depleting therapies in prostate cancer: new agents for an established target. Lancet Oncol (2009) 10(10):981-91. doi:10.1016/S1470-2045(09)70229-3

25. Attard G, Reid AH, A'Hern R, Parker C, Oommen NB, Folkerd E, et al. Selective inhibition of CYP17 with abiraterone acetate is highly active in the treatment of castration-resistant prostate cancer. J Clin Oncol (2009) 27(23):3742-8. doi:10.1200/JCO.2008.20.0642

26. Attard G, Reid AH, Yap TA, Raynaud F, Dowsett M, Settatree S, et al. Phase I clinical trial of a selective inhibitor of CYP17, abiraterone acetate, confirms that castration-resistant prostate cancer commonly remains hormone driven. J Clin Oncol (2008) 26(28):4563-71. doi:10.1200/JCO.2007.15.9749

27. Raghavan D, Klein EA. Prostate cancer: moving forward by reinventing the wheel but this time it is round. J Clin Oncol (2008) 26(28):4535-6. doi:10.1200/JCO. 2008.18.3145

28. Mostaghel EA, Montgomery B, Nelson PS. Castration-resistant prostate cancer: targeting androgen metabolic pathways in recurrent disease. Urol Oncol (2009) 27(3):251-7. doi:10.1016/j.urolonc.2009.03.016

29. Thomas LN, Douglas RC, Lazier CB, Too CK, Rittmaster RS, Tindall DJ. Type 1 and type 2 5alpha-reductase expression in the development and progression of prostate cancer. Eur Urol (2008) 53(2):244-52. doi:10.1016/j.eururo.2007.10. 052

30. Thomas LN, Douglas RC, Lazier CB, Gupta R, Norman RW, Murphy PR, et al. Levels of 5alpha-reductase type 1 and type 2 are increased in localized high grade compared to low grade prostate cancer. J Urol (2008) 179(1):147-51. doi:10.1016/j.juro.2007.08.155

31. Thomas LN, Lazier CB, Gupta R, Norman RW, Troyer DA, O’Brien SP, et al. Differential alterations in 5alpha-reductase type 1 and type 2 levels during development and progression of prostate cancer. Prostate (2005) 63(3):231-9. doi:10.1002/pros.20188

32. Locke JA, Nelson CC, Adomat HH, Hendy SC, Gleave ME, Guns ES. Steroidogenesis inhibitors alter but do not eliminate androgen synthesis mechanisms during progression to castration-resistance in LNCaP prostate xenografts. J Steroid Biochem Mol Biol (2009) 115(3-5):126-36. doi:10.1016/j.jsbmb.2009. 03.011

33. Locke JA, Guns ES, Lubik AA, Adomat HH, Hendy SC, Wood CA, et al. Androgen levels increase by intratumoral de novo steroidogenesis during progression of castration-resistant prostate cancer. Cancer Res (2008) 68(15):6407-15. doi:10.1158/0008-5472.CAN-07-5997

34. Parker C. What (if anything) to do about low-risk prostate cancer. Lancet (2012) 379(9821):1078-80. doi:10.1016/S0140-6736(12)60066-X

35. Nishiyama T, Ikarashi T, Hashimoto Y, Wako K, Takahashi K. The change in the dihydrotestosterone level in the prostate before and after androgen deprivation therapy in connection with prostate cancer aggressiveness using the Gleason score. J Urol (2007) 178(4 Pt 1):1282-8. doi:10.1016/j.juro.2007.05.138

36. Nishiyama T, Ikarashi T, Hashimoto Y, Suzuki K, Takahashi K. Association between the dihydrotestosterone level in the prostate and prostate cancer aggressiveness using the Gleason score. J Urol (2006) 176(4 Pt 1):1387-91. doi:10.1016/j.juro.2006.06.066

37. Nishiyama T, Hashimoto Y, Takahashi K. The influence of androgen deprivation therapy on dihydrotestosterone levels in the prostatic tissue of patients with 
prostate cancer. Clin Cancer Res (2004) 10(21):7121-6. doi:10.1158/1078-0432. CCR-04-0913

38. Rainey WE, Nakamura Y. Regulation of the adrenal androgen biosynthesis. J Steroid Biochem Mol Biol (2008) 108(3-5):281-6. doi:10.1016/j.jsbmb.2007. 09.015

39. Shirotake S, Miyajima A, Kosaka T, Tanaka N, Kikuchi E, Mikami S, et al. Regulation of monocyte chemoattractant protein-1 through angiotensin II type 1 receptor in prostate cancer. Am J Pathol (2012) 180(3):1008-16. doi:10.1016/j. ajpath.2011.11.027

40. Kosaka T, Miyajima A, Shirotake S, Suzuki E, Kikuchi E, Oya M. Long-term androgen ablation and docetaxel up-regulate phosphorylated Akt in castration resistant prostate cancer. J Urol (2011) 185(6):2376-81. doi:10.1016/j.juro.2011. 02.016

41. Hasegawa M, Miyajima A, Kosaka T, Yasumizu Y, Tanaka N, Maeda T, et al. Low-dose docetaxel enhances the sensitivity of S-1 in a xenograft model of human castration resistant prostate cancer. Int J Cancer (2012) 130(2):431-42. doi:10.1002/ijc.26012

42. Kosaka T, Miyajima A, Shirotake S, Kikuchi E, Oya M. Phosphorylated Akt up-regulates angiotensin II type-1 receptor expression in castration resistant prostate cancer. Prostate (2011) 71(14):1510-7. doi:10.1002/pros.21367

43. Kosaka T, Miyajima A, Shirotake S, Kikuchi E, Hasegawa M, Mikami S, et al. Ets-1 and hypoxia inducible factor-1 alpha inhibition by angiotensin II type-1 receptor blockade in hormone-refractory prostate cancer. Prostate (2010) 70(2):162-9. doi:10.1002/pros. 21049

44. Kosaka T, Miyajima A, Takayama E, Kikuchi E, Nakashima J, Ohigashi T, et al. Angiotensin II type 1 receptor antagonist as an angiogenic inhibitor in prostate cancer. Prostate (2007) 67(1):41-9. doi:10.1002/pros.20486

45. Kosaka T, Miyajima A, Nagata H, Maeda T, Kikuchi E, Oya M. Human castration resistant prostate cancer rather prefer to decreased 5alpha-reductase activity. Sci Rep (2013) 3:1268. doi:10.1038/srep01268

46. Zhau HY, Chang SM, Chen BQ, Wang Y, Zhang H, Kao C, et al. Androgenrepressed phenotype in human prostate cancer. Proc Natl Acad Sci U S A (1996) 93(26):15152-7. doi:10.1073/pnas.93.26.15152
47. Cinar B, Koeneman KS, Edlund M, Prins GS, Zhau HE, Chung LW. Androgen receptor mediates the reduced tumor growth, enhanced androgen responsiveness, and selected target gene transactivation in a human prostate cancer cell line. Cancer Res (2001) 61(19):7310-7.

48. Chuu CP, Hiipakka RA, Fukuchi J, Kokontis JM, Liao S. Androgen causes growth suppression and reversion of androgen-independent prostate cancer xenografts to an androgen-stimulated phenotype in athymic mice. Cancer Res (2005) 65(6):2082-4. doi:10.1158/0008-5472.CAN-04-3992

49. Chuu CP, Kokontis JM, Hiipakka RA, Fukuchi J, Lin HP, Lin CY, et al. Androgen suppresses proliferation of castration-resistant LNCaP 104-R2 prostate cancer cells through androgen receptor, Skp2, and c-Myc. Cancer Sci (2011) 102(11):2022-8. doi:10.1111/j.1349-7006.2011.02043.x

50. Chuu CP, Hiipakka RA, Kokontis JM, Fukuchi J, Chen RY, Liao S. Inhibition of tumor growth and progression of LNCaP prostate cancer cells in athymic mice by androgen and liver X receptor agonist. Cancer Res (2006) 66(13):6482-6. doi:10.1158/0008-5472.CAN-06-0632

Conflict of Interest Statement: The authors declare that the research was conducted in the absence of any commercial or financial relationships that could be construed as a potential conflict of interest.

Received: 15 April 2014; paper pending published: 12 May 2014; accepted: 29 August 2014; published online: 16 September 2014.

Citation: Kosaka T, Miyajima A and Oya M (2014) Is DHT production by $5 \alpha$-reductase friend or foe in prostate cancer? Front. Oncol. 4:247. doi: 10.3389/fonc.2014.00247

This article was submitted to Genitourinary Oncology, a section of the journal Frontiers in Oncology.

Copyright $(\odot) 2014$ Kosaka, Miyajima and Oya. This is an open-access article distributed under the terms of the Creative Commons Attribution License (CC BY). The use, distribution or reproduction in other forums is permitted, provided the original author(s) or licensor are credited and that the original publication in this journal is cited, in accordance with accepted academic practice. No use, distribution or reproduction is permitted which does not comply with these terms. 